\title{
METODE PEMBELAJARAN BAHAN MAGNET DAN IDENTIFIKASI KANDUNGAN SENYAWA PASIR ALAM MENGGUNAKAN PRINSIP DASAR FISIKA
}

\author{
Sunaryo dan Wira Widyawidura \\ (FMIPA Universitas Negeri Jakarta, Kampus B, Jalan Pemuda No. 10 \\ Rawamangun Jakarta, Indonesia 13220)
}

\begin{abstract}
A Method in Learning Magnetic Substance Characteristics and Identifying Natural Sand Compound Contents Through Basic Principles in Physics. This study was conducted by separating ferrate sand from natural sand in an area in Indramayu Regency in the form of the titanomagnetite Fe2.5 $\mathrm{Ti}_{0.5} \mathrm{O}_{4}$ compound by means of a magnetic separator with a power of 0.3 tesla. Using this method, the titanomagnetite content of the natural sand was capable of being improved from 32\% to 63.6\% (for sand in River Cimanuk's tributary) based on the analysis using XRD (X-Ray Difractometer) using the GSAS (General Structure Analisis System) program with a Chi ${ }^{2}$ of 1.454 and Wrp as a correction factor for the difference in the intensity of the two patterns was $0.1142(11.42 \%)$. The value of $\mathrm{Chi}^{2}$ which was almost 1 dan and that of Wrp which was almost $10 \%$ showed that the data were acceptable (with a probability of -1.1 ). To enhance the titanomagnetite content of the separation product, an extraction-solving process was conducted using $\mathrm{HCl} 32 \%$ and $\mathrm{NH}_{4} \mathrm{OH} 25 \%$. The results of the analysis using XRF (X-Ray Flourosence) showed that the content which was most probably a titanomagnetite compound increased its weight fraction to almost $100 \%$.
\end{abstract}

Keywords: ferrate sand, titanomagnetite, permanent magnet

\section{PENDAHULUAN}

Model pengajaran fisika material magnetik sudah mulai dikenalkan ditingkat pendidikan dasar dan menengah untuk memotivasi proses belajar yang kreatif dan dinamis sehingga diperlukan banyak metode agar dapat mencapai tujuan pengajaran. Pada materi tertentu diperlukan model yang memerlukan dukungan teknologi, lingkungan dan metode yang tepat, untuk dapat mempermudah pemahaman materi fisika tersebut. Di samping itu, prinsip dasar fisika perlu menjadi landasan ulasan dalam menganalisis bahan ajar sehingga dengan adanya pemahaman teori serta praktek analisis lapangan akan menambah motivasi dalam proses pengajaran. Berikut salah satu upaya dengan model pengajaran yang mengacu pada teknologi dan lingkungan dalam menganalisis struktur material yang terdapat pada pasir di daerah muara sungai Kabupaten Indramayu.

Pasir besi yang mengandung mineral-mineral magnetik banyak terdapat di 
daerah-daerah pantai, sungai, dan pegunungan vulkanik. Indonesia yang merupakan negara kepulauan sudah pasti memiliki muara-muara sungai yang banyak di samping wilayah pantai yang sangat luas ${ }^{[1]}$. Akan tetapi, pemanfaatan pasir besi yang ada di Indonesia, khususnya di daerah pantai utara P. Jawa masih sangat kurang disebabkan minimnya pengetahuan dan penelitian di bidang tersebut .

Pasir adalah mineral endapan (sedimen) yang memiliki ukuran butir 0,074 hingga $0,075 \mathrm{~mm}$, dengan ukuran kasar (5 mm hingga $3 \mathrm{~mm}$ ) dan ha-lus $(<1$ $\mathrm{mm}$ ). Berdasarkan lokasi endapannya, dimungkinkan terjadinya perbedaan karakter fisis kandungan pasir mineral seperti $\mathrm{Fe}, \mathrm{Ti}, \mathrm{Mg}, \mathrm{Si}$, dsb [2]. Senyawa magnetite $\left(\mathrm{Fe}_{3} \mathrm{O}_{4}\right)$ adalah suatu mineral magnetik yang biasanya terdapat di daerah pantai atau sungai. Di alam, senyawa ini dapat berasal dari variannya yaitu senyawa titanomagnetite yang rumus umumnya ditulis $\mathrm{Fe}_{3-\mathrm{x}} \mathrm{Ti}_{\times} \mathrm{O}_{4}$

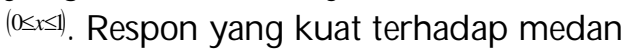
magnet luar menjadikan magnetite sangat berguna untuk kepentingan riset dan dalam dunia industri yang berbasis kemagnetan di antaranya dalam hal rekayasa elektronika, pembuatan magnet permanen, industri baja, sampai untuk pembuatan thin film (Julianto, 2002).

Penelitian mengenai pengayaan senyawa titanomagnetite dari senyawasenyawa lain pada pasir alam dilakukan dalam rangka melaksanakan kebutuhan untuk mengetahui bagaimana proses

Pengayaan titanomagnetite itu berangsung hingga didapatkan senyawa titanomagnetite yang yang maksimal.
Selain aplikasinya sebagai bahan baku industri baja, senyawa titanomagnetite ini diharapkan dapat menjadi bahan baku paduan untuk mendapatkan senyawa magnetite ataupun unsur titaniumnya (Brown et. al., 1994).

Dibutuhkan perlakuan khusus untuk memisahkan senyawa besi oksida seprti titanomagnetite dari senyawasenyawa lain yaitu dengan separasi magnetik dengan menggunakan medan magnet yang tepat, dengan bantuan metode penghancuran secara mekanik, ekstraksi kimia, pencucian, dan juga perlakuan panas (heat treatment) dengan temperatur tertentu. (Omar, 1975: 451456)

\section{SIFAT-SIFAT KEMAGNETAN}

Diamagnetik adalah salah satu sifat dari semua material. Sifat ini disebabkan oleh medan magnet luar dan gerakan elektron dalam mengorbit inti. Karena elektron-elektron membawa muatan, mereka akan melakukan gaya Lorenz pada saat bergerak melewati medan magnet. Contoh kasus mengenai ini adalah ketika elektron bergerak searah jarum jam dengan sebuah orbit lingkaran yang berpusat pada origin dan terletak di bidang $x y$ dengan sebuah medan magnet luar yang diberikan pada arah $+x$. Untuk $1 / 2$ orbit $(x>0)$, gaya Lorenz akan sejajar dengan sumbu $-\mathrm{z}$, dan untuk setengah yang lain ia akan sejajar dengan sumbu $+z$.

Sebuah torsi kemudian akan timbul sejajar dengan sumbu y menye-babkan orbit mempresisikan dirinya sepanjang arah medan. Hal ini disebut dengan Larmour Precision yang akan menimbulkan sebuah momen magnetik di arah 
yang berlawanan dengan medan magnet yang diberikan. Pada bahan diamagnetik, efek ini sangat kecil sehingga hampir dapat diabaikan. Besarnya sekitar 100 kali lebih kecil dari bahan paramagnetik dan 1.000 kali lebih kecil dari feromagnetik. Quartz dan air (water) merupakan contoh dari bahan diamagnetik. Sifat diamagnetik tak tergantung dari temperatur, sedangkan sifat paramagnetik dan feromagnetik berkurang secara drastis jika bahan yang mengandung sifat tersebut dipanaskan (Evans, 2003:7).

Dalam konteks kemagnetan, bahan paramagnetik lebih penting disbandingkan dengan diamagnetik. Hal ini muncul dari gambaran bahwa elektron seolah-olah berputar (berspin) di sekitar sumbunya sambil mengorbit inti atom. Hal ini menimbulkan sebuah spin magnetik sebagai tambahan dari momen orbital magnetiknya. Momen magnetik total pada sebuah atom diberikan oleh penjumlahan vektor dari momen-momen elektroniknya. Jika momen magnetik, spin dan orbital pada sebuah atom saling menghilangkan, maka atom tersebut mempunyai momen magnetik sebesar 0 . Inilah yang disebut sifat diamagnetik. Jika penghilangannya hanya sebagian, maka atom akan mempunyai momen magnetik permanen. Inilah yang disebut dengan paramagnetik. Contoh dari bahan paramagnetik adalah biotite, pyrite, dan siderite

Feromagnetik lebih kuat disbandingkan dengan diamagnetik dan paramagnetik. Secara khusus, berhubungan dengan unsur besi, nikel, dan cobalt dan juga mineral-mineral besi oksida. Karena adanya subkulit 3d yang tidak terisi, atom-atom besi akan menghasilkan sebuah momen magnetik pada 4 magneton Bohr $\left(4 \mu_{B}\right)$. Pada kisi kristal material feromagnetik, atom-atom yang berdekatan saling mendekati bersama secara tepat sehingga beberapa orbit-orbit elektronnya akan overlapping dan terjadilah sebuah interaksi yang kuat.

Fenomena ini disebut dengan $e x-$ change couping yang maksudnya adalah selain terarah secara acak, momenmomen magnetik dari sebuah atom di dalam kisi terarahkan dan memberikan sebuah magnetisasi yang kuat. Pengaturan ini biasanya digambarkan dengan kumpulan panah-panah dengan panjang yang sama dan sejajar (gambar 2.1) (Evans, 2003:8). Ini merupakan gambaran mudah dari feromagnetik.

Pada Antiferomagnetik, momenmomen magnetik pada atom seluruhnya mempunyai kekuatan yang sama, tetapi atom-atom tetangganya mempunyai arah momen yang berkebalikan. Meskipun memiliki exchange couping yang kuat, material jenis ini memiliki magnetisasi total sebesar nol. Pada beberapa kasus, sebuah magnetisasi lemah dapat muncul dari cacat kisi dan vacancies atau dari situasi di mana momen-momen atomiknya sedikit miring.

Ada hal penting dimana exchange coupling beraksi, yaitu dengan memberikan fenomena fermagnetik. Di sini, kisikisi kristal terdiri dari 2 jenis tempat dengan kation-kation pada keadaan koordinasi yang berbeda. Peristiwa ini digambarkan dengan 2 tipe panah, yang satu lebih panjang dari yang lain. Sebagaimana pada bahan antiferomagnetik, 2 setnya berlawanan tetapi mag- 
netisasi yang kuat dapat secara jelas muncul jika 2 tipenya tidak sama.

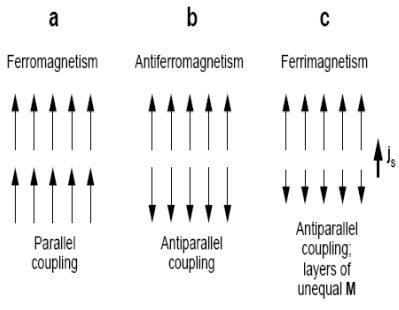

Gambar 2.1. a) Feromagnetik, b) Antiferomagnetik, c) Ferimagnetik

\section{SUSEPTIBILITAS MAGNETIK}

Kita anggap sebuah material yang ingin kita teliti, ditempatkan pada sebuah medan magnet yang serba sama (H) dan kemudian akan didapatkan sebuah medan magnet yang serba sama. Suseptibilitas magnetnya $(\kappa)$ didefinisikan sebagai magnetisasi yang didapatkan per unit medan,

$$
\kappa=M / H
$$

Dalam SI, M dan H satuannya adalah $\mathrm{A} / \mathrm{m}$, sehingga $\kappa$ tidak mempunyai satuan. Dengan kata lain $\kappa$ disebut suseptibilitas volume. Untuk mendapatkan apa yang disebut dengan suseptibilitas massa, maka $\kappa$ kita bagi dengan massa jenis $(\rho)^{\prime}$

$$
\chi=\kappa / \rho
$$

Karena $\kappa$ tidak berdimensi maka $\chi$ mempunyai satuan berkebalikan dengan densitas yaitu $\mathrm{m}^{3} / \mathrm{kg}$. Sedangkan kerapatan fluks magnetik atau induksi magnetik (B) menyatakan jumlah garis-garis gaya medan magnet yang melalui satu luasan. Besaran B ini mempunyai satuan Tesla dan mempunyai hubungan dengan medan $\mathrm{H}$ dan $\mathrm{M}$ sbb. :

$$
\begin{aligned}
B & =\mu_{o}(H+M) \quad \text { atau } \\
& =\mu_{o} M(1+1 / \kappa)
\end{aligned}
$$

dimana $\mu_{o}=$ permeabilitas ruang hampa $=4 \cdot 10^{-7} \mathrm{~N} / \mathrm{A}^{2}$

Pada beberapa situasi, kita lebih baik bila menggunakan istilah momen magnetik pada seluruh benda. Kemudahan diberikan oleh hasil dari MV, dimana V adalah volume total, menghasilkan satuan $\mathrm{am}^{2}$.

Pada bahan diamagnetik, proses dari elektron-elektron memberikan peningkatan nilai dari $x$ dalam pangkat $10^{-}$ ${ }^{8} / \mathrm{m}^{3} / \mathrm{kg}$. Air (water) adalah salah satu yang paling kuat dengan $x=-0,90 \times 10^{-8}$ $\mathrm{m}^{3} / \mathrm{kg}$. Banyak batuan biasa yang terbentuk dari silika, seperti quartz dan calcite, mempunyai nilai sekitar setengah dari besarnya.

Pada material paramagnetik, temperatur sangatlah mempengaruhi suseptibilitas seperti yang digambarkan oleh hukum Curie :

$$
\kappa=C / T
$$

Di mana $\mathrm{T}$ adalah temperatur absolut dan $\mathrm{C}$ adalah konstanta Curie. Pada suhu ruang, energi termal cenderung mengacaukan penyearahan ribuan kali lebih besar daripada energi magnetik yang mencoba menyearahkan momen-momen magnetik, $M$.

Grafik $M$ versus $H$ untuk sebuah bahan paramagnet menunjukkan hubungannya yang linier, dan kemiringannya merupakan suseptibilitas (gambar 2.2) (abd El-All, 2004). Suseptibilitas massa $x$ pada bentuk batuan silikat biasa seperti, fayalite atau biotite dan iron sulfide pyrate, adalah sekitar $5 \times 10^{-7} \mathrm{~m}^{3} \mathrm{~kg}$ 


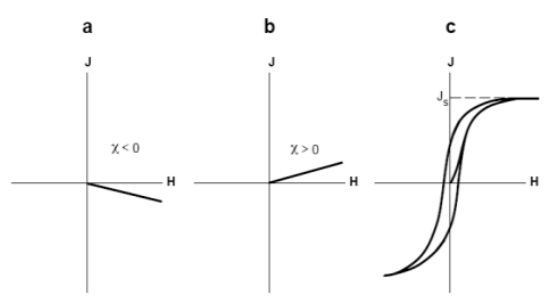

Gambar 2.2: Grafik Magnetisasi J (M) Versus Medan Luar H pada (a) Diamagnetik, (b) Paramagnetik, (c) Feromagnetik

Pada bahan feromagnetik, hubungan antara $\mathrm{M}$ dan $\mathrm{H}$ lebih rumit daripada diamagnetik dan paramagnetik. Salah satu perbedaan yang penting adalah bahwa ia mudah mencapai keadaan saturasi, dimana seluruh momen-momen atomiknya terarahkan. Pada beberapa kasus, keadaan saturasi ini dapat terjadi pada medan yang berada pada skala laboratorium elektromagnet yaitu berada pada medan rendah (kurang dari $10^{3} \mathrm{~A} / \mathrm{m}$ ) dekat origin dari grafik $\mathrm{M}-\mathrm{H}$.

Slope (kemiringannya) kemudian memberikan low-field suceptibility (disebut juga initial suceptibility, tetapi kata initial di sini sering dihilangkan). Yang lebih penting dari objek ini adalah mempunyai kecendrungan yang kuat untuk mendemagnetisasi dirinya sendiri. Pengukuran untuk suseptibilitasnya diberikan oleh :

$$
\kappa=\kappa_{i} /\left(1+N \kappa_{i}\right)
$$

Dimana $\kappa_{i}$ adalah actual intrinsic suceptibility yang akan diukur dalam absennya medan demagnetisasi dan $\mathrm{N}$ adalah faktor yang dipengaruhi oleh bentuk bulir.

\section{METODE}

Model Pengajaran mengenai bahanbahan magnetik dilakukan melalui proses dengan dukungan laboratorium dan dukungan sampel yang diambil dari satu lokasi tertentu. Proses pembelajaran dilakukan melalui eksperimen, sehingga kegiatan proses pembelajaran melalui tahapan: (1) penjelasan teori untuk melakukan analisis praktikum dengan tujuan tertentu; dan (2) eksperimen untuk melakukan analisis lanjut dalam pencapaian dengan langkah-langkah sebagai berikut.

Sampel pasir alam diambil di daerah muara sungai Cimanuk (pantai Waledan) dan pantai Balongan, Indramayu, Jawa Barat dan untuk masing-masing daerah pengambilan sampel (muara sungai dan pantai) diambil sampel dari 4 titik yang berbeda yang membentuk garis simetri dengan jarak masing-masing titik yaitu $5 \mathrm{~m}$ dan dengan kedalaman $30 \mathrm{~cm}$. (Gambar 1).

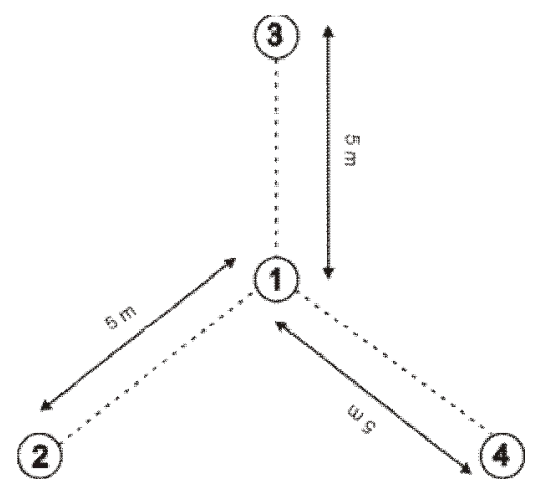

Gambar 1: Skema Pengambilan Sampel

Proses preparasi sampel dilakukan di Laboratorium Fisika Material FMIPA UNJ. Masing-masing sampel berupa pasir muara, pasir pantai, ditakar seberat 
500 gr dengan neraca timbang digital yang sudah dikalibrasi kemudian tempatkan pasir tersebut di atas wadah yang lebar lalu diaduk sampai merata.

Untuk melakukan separasi kandungan besi oksida pada sample-sampel pasir alam tersebut, digunakan magnet batang permanen dengan kekuatan sekitar $38,9 \mathrm{~kJ} / \mathrm{m}^{3}$ yang sudah dilapisi kertas plastik dengan ketebalan 0,1 $\mathrm{mm}$. Magnet didekatkan ke seluruh bagian pasir dengan jarak sekitar $1,5 \mathrm{~cm}$ dari pasir sampai kita menganggap semua pasir besinya terangkat dan memisahkan pasir besi tersebut ke wadah yang lain. Separasi dilakukan berulang-ulang terhadap pasir besi yang terangkat tersebut dengan membuat lebih jauh jarak magnet dengan sampel. sampai kita mendapatkan pasir besi yang warnanya hitam (sedikit pengotornya) dan pasir besi hasil separasi terakhir ditimbang.

Dari hasil penimbangan pasir besi hasil separasi terakhir, dipilih sampel yang mempunyai massa paling banyak untuk diteruskan ke proses selanjutnya. Sampel pasir besi tersebut kemudian dimasukkan ke dalam vibrational ball mill (VBM) yang menggunakan 10 bola baja dengan perbandingan 100 gr sampel : 10 boladanmenghidupkanya selama 50 menit untuk melakukan penggerusan atau milling (sebelumnya, tabung VBM dan bola-bola baja dibersihkan dulu dengan toluena). Setelah 50 menit, sampel dituangkan ke dalam wadah plastik yang lebar kemudian diseparasi kembali lalu sampel yang terangkat dan sisanya ditimbang kembali.

Sampel hasil milling tersebut diambil sebanyak 10 gr untuk dilakukan proses ekstraksi secara kimia dengan $20 \mathrm{ml}$ la- rutan $\mathrm{HCl}$ konsentrasi 32\%. Langkah ini menghasilkan larutan $\mathrm{FeCl}_{2}$ ataupun $\mathrm{FeCl}_{3}$ (Aji, 2007). Proses tersebut mengikuti persamaan reaksi:

$$
\mathrm{Fe}_{3} \mathrm{O}_{4}+8 \mathrm{HCl} \rightarrow \mathrm{FeCl}_{2}+2 \mathrm{FeCl}_{3}+4 \mathrm{H}_{2} \mathrm{O}
$$

Tahap berikutnya adalah menuangkan larutan amonium hidroksida $\left(\mathrm{NH}_{4} \mathrm{OH}\right)$ perlahan-lahan ke dalam larutan $\mathrm{FeCl}_{2}$ ataupun $\mathrm{FeCl}_{3}$ sampai terbentuk endapan magnetite ataupun titanomagnetite (Aji, 2007). Proses tersebut mengikuti persamaan reaksi

$$
\begin{gathered}
\mathrm{FeCl}_{2}+2 \mathrm{FeCl}_{3}+8 \mathrm{NH}_{4} \mathrm{OH} \rightarrow \mathrm{Fe}_{3} \mathrm{O}_{4}+ \\
8 \mathrm{NH}_{4} \mathrm{Cl}+\mathrm{H}_{2} \mathrm{O}
\end{gathered}
$$

Untuk menghilangkan beberapa garam pengotor, endapan titanomagnetite yang terbentuk dicuci dengan menambahkan sedikit air dan kemudian diproses melalui alat sentrifugal selama 3 menit dengan putaran $6.500 \mathrm{rpm}$ dan 6 menit dengan putaran $13.000 \mathrm{rpm}$.

Sampel-sampel diidentifikasi unsurunsurnya melalui peralatan XRF (X-Ray Flourocencies). Tujuannya yaitu untuk memperoleh data kualitatif unsur-unsur yang terkandung di dalam sampel dan juga persen beratnya. Kemudian untuk memastikan fasa-fasa yang terkandung di dalamnya dan besar kandungannya maka sampel diuji dengan alat XRD (XRay Diffraction). Proses pengujian sampel dengan XRD dan XRF dilakukan di Laboratorium Ilmu Material, Universitas Indonesia, Salemba.

Hasil yang diperoleh dari XRD kemudian dianalisis dengan meggunakan program GSAS (General Structure Analysis System) untuk menentukan fraksi berat fasa-fasanya secara teliti dengan mencocokkan terlebih dahulu data hasil keluaran XRD dengan kartu-kartu data 
yang ada di dalam program $P C P D F W I N$ (ICDD) untuk mendapatkan nilai parameter kisi seperti a, b, c, dan space group agar hasil yang dicapai maksimal.

\section{HASIL DAN DISKUSI}

Pada proses pembelajaran melalui model eksperimen yang didukung sampel-sampel berupa pasir alam dari suatu daerah (Kab. Inramayu) diperoleh infor- masi sebagai berikut. Pada sampel, untuk keempat titik yang diambil di masing-masing daerah (pantai dan muara), setelah dilakukan pemisahan pasir besinya dengan menggunakan magnet permanen berkekuatan $0,3 \mathrm{~T}$, didapatkan hasil sebagai berikut.

\section{Tabel 1: Jumlah Massa Pasir Besi yang Terangkat dengan Magnet Permanen 0,3 T untuk Sampel Pasir Muara}

\begin{tabular}{lllll}
\hline No. & $\begin{array}{c}\text { Kode } \\
\text { Sampel }\end{array}$ & $\begin{array}{c}\text { Berat } \\
\text { awal } \\
\text { (gr) }\end{array}$ & $\begin{array}{c}\text { Terangkat } \\
\text { (gr) }\end{array}$ & \multicolumn{1}{c}{ Sisa (gr) } \\
\hline 1 & 1M1 & 500 & 26,1 & 473,9 \\
2 & 2M1 & 500 & 20,94 & 479,06 \\
3 & 3M1 & 500 & 203,9 & 296,1 \\
4 & 4M1 & 500 & 9,15 & 490,85 \\
\hline \multicolumn{4}{l}{ Rata-rata massa yang terangkat: 65,0225 gr } \\
\hline
\end{tabular}

Tabel 2: Jumlah Massa Pasir Besi yang Terangkat dengan Magnet Permanen 0,3 T untuk Sampel Pasir Pantai

\begin{tabular}{lllll}
\hline No. & $\begin{array}{l}\text { Kode } \\
\text { Sampel }\end{array}$ & $\begin{array}{l}\text { Berat } \\
\text { awal } \\
\text { (gr) }\end{array}$ & $\begin{array}{l}\text { Terangkat } \\
\text { (gr) }\end{array}$ & $\begin{array}{l}\text { Sisa } \\
\text { (gr) }\end{array}$ \\
\hline 1 & 1P1 & 500 & 6,35 & 493,65 \\
2 & $2 \mathrm{P} 1$ & 500 & 9,892 & 490,108 \\
3 & $3 \mathrm{P} 1$ & 500 & 7,112 & 492,888 \\
4 & $4 \mathrm{P} 1$ & 500 & 5,244 & 494,756 \\
\hline \multicolumn{4}{l}{ Rata-rata massa yang terangkat: } & 5,8385 gr \\
\hline
\end{tabular}

Dari data-data massa sampel di atas dapat dilihat bahwa untuk jenis pasir muara sungai, distribusi penyebaran mineral pasir besi dalam area tertentu berdasarkan kedalaman dan jaraknya ternyata tidak merata. Hal ini dapat dilihat dari besarnya selisih massa pasir besi yang terangkat di antara sampel berkode M. Untuk pasir pantai, penyebarannya hampir merata. Sampel yang digunakan untuk penelitian tahap selanjutnya sampel dengan massa terangkat paling banyak yaitu sampel 3M1 dan 
2P1 yang kemudian dinamai menjadi 3M2 dan 2P2.

Setelah dilakukan penembakan dengan XRF untuk sampel 3M1 (yang diambil di alam), 3M2 (pemisahan dengan separator magnet), dan 2P1 (yang diambil di alam) maka didapatkan unsur-unsur dengan persen berat sebagai berikut.

Tabel 3: Senyawa-senyawa dan Persen Beratnya dari Hasil XRF untuk Sampel Pasir Muara Sungai Cimanuk (3M1 dan 3M2) dan Pasir Pantai Balongan (2P1)

\begin{tabular}{|c|c|c|c|}
\hline Un & $\begin{array}{c}\text { Psr. } \\
\text { Muara } \\
(3 \mathrm{M} 1)\end{array}$ & $\begin{array}{c}\text { Psr. } \\
\text { Muara } \\
(3 \mathrm{M} 2)\end{array}$ & $\begin{array}{c}\text { Psr. } \\
\text { Pantai } \\
(2 \mathrm{P} 1)\end{array}$ \\
\hline sur & $\begin{array}{c}\text { Persen } \\
\text { Berat } \\
(w t \%)\end{array}$ & $\begin{array}{c}\text { Persen } \\
\text { Berat } \\
(w t \%)\end{array}$ & $\begin{array}{c}\text { Persen } \\
\text { Berat } \\
(w t \%)\end{array}$ \\
\hline $\mathrm{Si}$ & 35,5312 & 12,2303 & 54,6084 \\
\hline $\mathrm{Fe}$ & 33,8767 & 65,204 & 12,6881 \\
\hline $\mathrm{Al}$ & 12,4135 & 6,2613 & 18,6359 \\
\hline $\mathrm{Ti}$ & 6,2539 & 10,9418 & 1,2059 \\
\hline $\mathrm{Mg}$ & 6,0086 & 3,0988 & 4,1292 \\
\hline $\mathrm{Ca}$ & 4,6347 & 1,0796 & 7,2863 \\
\hline K & 0,4689 & -- & 1,1779 \\
\hline V & 0,2889 & 0,5759 & 0,0591 \\
\hline $\mathrm{Mn}$ & 0,214 & 0,0617 & 0,1635 \\
\hline$S$ & 0,1718 & 0,1246 & -- \\
\hline $\mathrm{Cr}$ & 0,1377 & 0,2091 & - \\
\hline $\mathrm{P}$ & -- & 0,2129 & --- \\
\hline $\mathrm{Zr}$ & $-\ldots$ & --- & 0,0456 \\
\hline
\end{tabular}

Tabel 3 memerlihatkan bahwa pada sampel 3M1, yaitu sampel awal sebelum separasi magnetik, unsur yang paling dominan fraksi beratnya adalah Si dan Fe. Hal ini memperlihatkan bahwa unsur Fe pada senyawa besi oksida yang rensponsif terhadap medan magnet jumlahnya cukup banyak yaitu 33,8767 wt $\%$.

Pada sampel 2P1 (tabel 3), senyawa yang dominan adalah senyawa $\mathrm{Si}, \mathrm{Al}$ dan Fe tetapi unsur Fe pada senyawa besi oksida yang rensponsif terhadap medan magnet jumlahnya sedikit. Ini sesuai dengan sedikitnya jumlah massa senyawa magnetik yang berhasil dipisahkan dengan separator magnet yaitu dengan rata-rata massa terangkat sebesar 5,8385 gr dari 500 gr. Karena mempunyai persen berat unsur Fe dan Ti yang lebih besar, maka proses pemisahan dan identifikasi sampel hanya terfokus pada sampel dari pasir muara (berkode M).

Setelah dilakukan proses pemisahan dengan menggunakan magnet permanen berkekuatan 0,3 T (sampel 3M2), maka dari tabel 3 menunjukkan bahwa jumlah persen berat senyawa yang mengandung unsur Fe dan Ti persen meningkat, sedangkan persen berat senyawa yang mengandung unsur Si menurun. Hal ini sesuai dengan perkiraan awal bahwa dengan intensitas magnet luar sebesar 0,3 T tersebut dapat menarik senyawa-senyawa magnetik besi oksida. Adanya unsur Ti yang ikut meningkat, memperlihatkan bahwa unsur Fe dan Ti kemungkinan berada dalam satu senyawa yaitu senyawa titanomagnetite.

Setelah dilakukan penembakan dengan XRD dan kemudian dilakukan pencocokan pola data difraksi sinar-X melalui software ICDD (International Crystalography Diffraction Data) dari beberapa situs database kristalografi ke- 
mudian dengan menggunakan program GSAS (General Structure Analysis System) untuk melakukan analisis pendekatan (fitting) dengan penghalusan antara pola-pola difraksi observasi dari hasil pengujian XRD (eksperimen) dan pola difraksi hasil perhitungan secara matematis untuk sampel 3M1 (yang diambil di alam), didapatkan grafik fitting dan normalisasi error sebagai berikut.

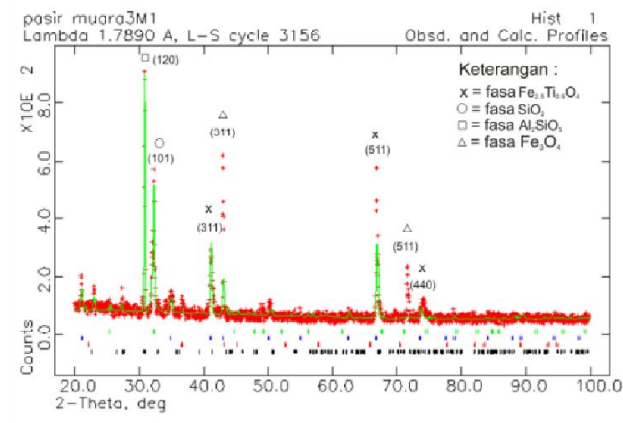

Gambar 2: Grafik Pola Difraksi Sinar-X melalui Perhitungan GSAS untuk Sampel 3M1

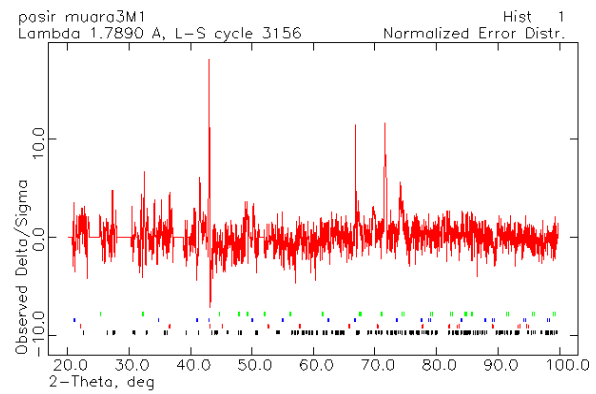

Gambar 3: Analisis Kesalahan Puncak Difraksi pada Sampel 3M1

Dari hasil perhitungan melalui GSAS, didapatkan nilai untuk persen berat masing-masing fase yang teridentifikasi untuk sampel 3M1 sebagai berikut.

\section{Tabel 4: Nilai Persen Berat Masing- masing Fase pada Sampel 3M1}

\begin{tabular}{ll}
\hline Senyawa & $\begin{array}{l}\text { Persen } \\
\text { Berat } \\
\%)\end{array}$ \\
\hline $\mathrm{SiO}_{2}$ & 46,840 \\
$\mathrm{Al}_{2} \mathrm{SiO}_{5}$ & 20,354 \\
$\mathrm{Fe}_{2.5} \mathrm{Ti}_{0.5} \mathrm{O}_{4}$ & 18,094 \\
$\mathrm{Fe}_{3} \mathrm{O}_{4}$ & 14,712 \\
\hline
\end{tabular}

Nilai Chi*2 dari pola di atas adalah 2,847 dan Wrp, sebagai faktor koreksi perbedaan tinggi intensitas kedua pola tersebut adalah 0,1922 (19,22\%). Nilai Chi**2 sebesar 2,847 dan Wrp mendekati $20 \%$ menyatakan data yang masih cukup besar tingkat kesalahannya. Dari grafik normalisasi error terlihat bahwa yang menjadi sumber kesalahan adalah pada sudut 2 theta sebesar $43^{\circ} ; 66,8^{\circ}$; dan $71,6^{\circ}$. Puncak pada sudut-sudut tersebut diduga kuat sebagai fase lain yang tidak dapat teridentifikasi melalui kartu-kartu data difraksi ICDD dan beberapa referensi lainnya.

Data-data di atas menunjukkan bahwa fase yang tertinggi adalah fase $\mathrm{SiO}_{2}$ dan $\mathrm{Al}_{2} \mathrm{SiO}_{5}$. Hal tersebut telah sesuai dengan data yang didapat dari analisis $X R F$ yang menyatakan bahwa pada sampel 3M1 senyawa yang mempunyai persen berat paling tinggi adalah senyawa yang mengandung unsur Si.

Senyawa-senyawa magnetik yang terkandung pada sampel ini adalah $\mathrm{Fe}_{2.5} \mathrm{Ti}_{0.5} \mathrm{O}_{4}$ dan $\mathrm{Fe}_{3} \mathrm{O}_{4}$ yang persen beratnya masih relatif kecil. Hal tersebut memang sesuai dengan analisis dengan menggunakan XRF, yang menyatakan 
bahwa persen berat unsur Fe sebagai unsur utama material magnetik pada sampel 3M1 adalah kecil (<50 Wt\%).

Proses milling (penggerusan) dengan $V B M$ dilakukan pada sampel M2 selama 50 menit dengan perbandingan 100 gr sampel: 10 bola. Hal ini agar mendapatkan butiran yang cukup halus dan merata. Kemudian dilakukan proses separasi ulang, maka diperoleh massa pasir magnetik yang terangkat sebagai berikut.

Tabel 5: Data Massa Pasir Magnetik yang Terangkat oleh Separator

\begin{tabular}{ccccc}
\hline No & $\begin{array}{c}\text { Kode } \\
\text { Sampel }\end{array}$ & $\begin{array}{c}\text { Berat } \\
\text { awal } \\
\text { (gr) }\end{array}$ & $\begin{array}{c}\text { Terangkat } \\
\text { (gr) }\end{array}$ & $\begin{array}{c}\text { Si } \\
(\mathrm{g})\end{array}$ \\
\hline 1 & M2 & 100 & 81,05 & 18 \\
\hline
\end{tabular}

Dari data-data tersebut dapat terlihat bahwa ternyata masih dapat dilakukan pemisahan pasir magnetik dari pengotornya dengan separator magnetik setelah proses milling berlangsung. Hal ini disebabkan peng-gerusan tersebut cukup efekif untuk memisahkan senyawa non-magnetik seperti $\mathrm{SiO}_{2}$ yang melekat pada senyawa magnetik. Sampel M2 yang berhasil dipisahkan kemudian secara diubah penamaannya menjadi 3M3.

Setelah dilakukan penembakan dengan XRD dan kemudian dilakukan pencocokan pola data difraksi sinar- $X$ melalui software ICDD dan beberapa situs database kristalografi, kemudian dengan menggunakan program GSAS untuk melakukan analisis pendekatan (fitting) dengan penghalusan antara pola-pola difraksi observasi dari hasil pengujian XRD (eksperimen) dan pola difraksi hasil perhitungan secara matematis untuk sampel 3M3 (setelah proses separasi dan milling) maka didapatkan grafik fitting dan normalisasi error sebagai berikut

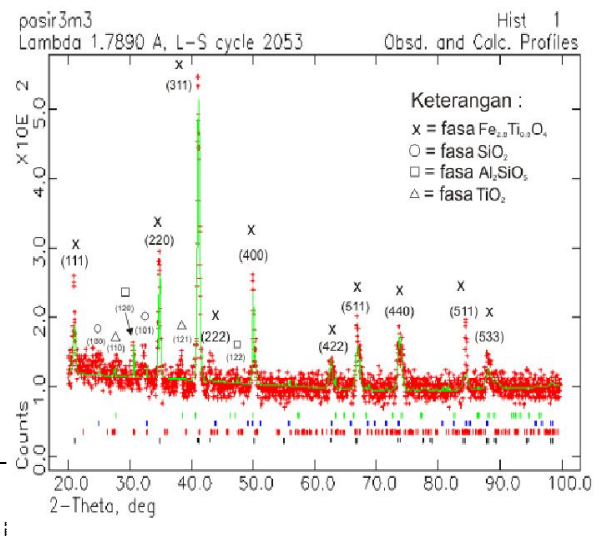

$\mathrm{Si}$

(8yambar 4: Grafik Pola Difraksi Sinar-X melalui Perhitungan GSAS untuk

Sampel 3M3

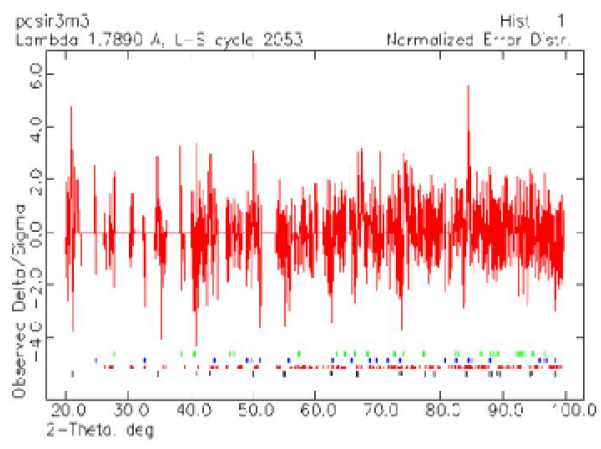

Gambar 6: Analisis Kesalahan Puncak

Difraksi pada Sampel 3M3

Dari hasil perhitungan melalui GSAS, didapatkan nilai untuk persen berat masing-masing fase yang teridentifikasi untuk sampel 3M3 sebagai berikut. 
Tabel 6: Nilai Persen Berat Masingmasing Fase pada Sampel 3M3

\begin{tabular}{ll}
\hline Senyawa & $\begin{array}{l}\text { Persen } \\
\text { Berat } \\
(\mathrm{wt} \%)\end{array}$ \\
\hline $\mathrm{Fe}_{2.5} \mathrm{Ti}_{0.5} \mathrm{O}_{4}$ & 82,255 \\
$\mathrm{SiO}_{2}$ & 10,612 \\
$\mathrm{Al}_{2} \mathrm{SiO}_{5}$ & 6,080 \\
$\mathrm{Ti}_{2} \mathrm{O}_{3}$ & 1,0531 \\
\hline
\end{tabular}

Nilai $\mathrm{Ch}^{* *} 2$ dari pola di atas adalah 1,416 dan wrp, sebagai faktor koreksi perbedaan tinggi intensitas kedua pola tersebut adalah 0,1126 (11,26\%) . Nilai $\mathrm{Chi}^{* * 2}$ mendekati 1 dan wrp mendekati $10 \%$ menyatakan data yang diperoleh dapat diterima (tingkat kesalahan $\sim 0,1$ ).

Data-data di atas menunjukkan bahwa fase yang tertinggi adalah fase Titanomagnetite $\left(\mathrm{Fe}_{2.5 \mathrm{Ti} 0.5} \mathrm{O}_{4}\right)$. Akan tetapi, fase $\mathrm{SiO}_{2}$ dan $\mathrm{Al}_{2} \mathrm{SiO}_{5}$ yang bersifat diamagnetik masih cukup besar persen beratnya (Total keduanya $=\sim 15 \%$ ). Keberadaannya ini diduga pada saat proses pemisahan dilakukan, senyawa titanomagetite-nya masih banyak yang masih terlingkupi oleh fase ini, sehingga pada saat fase titanomagnetite terangkat oleh magnet, fase ini pun juga ikut terangkat.

Dari hasil proses ekstraksi kimia dalam rangka peningkatan persen berat dari titanomagnetite untuk sampel 3M3 sebanyak 10 gr dengan menggunakan larutan $\mathrm{HCl}$ untuk mendapatkan larutan $\mathrm{FeCl}_{2}$ ataupun $\mathrm{FeCl}_{3}$ dan $\mathrm{NH}_{4} \mathrm{OH}$ untuk mendapatkan kembali fase titanomagnetite (sampel 3M4), didapatkan hasil dari penembakan XRF untuk sampel
3M4 sebagai sampel hasil ekstraksi tersebut sebagai berikut.

Tabel 7: Senyawa dan Persen Berat Hasil Analisis Grafik XRF untuk Sampel 3M4

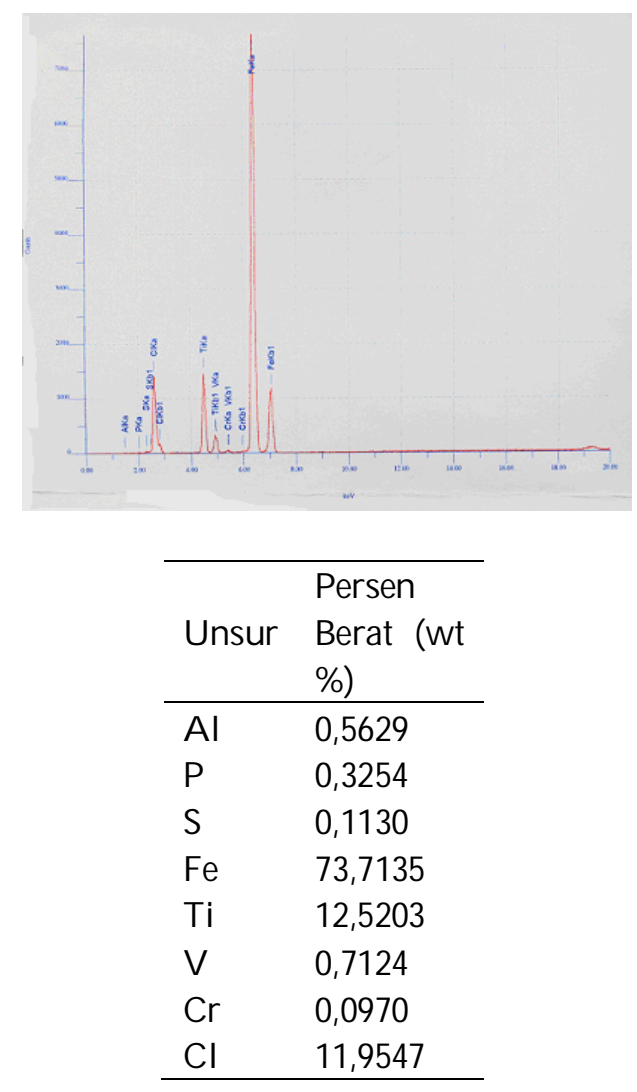

Dari data persen berat pada tabel di atas dapat dilihat bahwa unsur-unsur pengotor utama yaitu Si sudah hilang. Sedangkan unsur pengotor lainnya yaitu $\mathrm{Al}, \mathrm{P}, \mathrm{S}, \mathrm{V}, \mathrm{Cr}$ hanya menyisakan masing-masing tidak lebih dari $1 \mathrm{wt} \%$.

Hal ini menunjukkan bahwa ekstraksi kimia dengan menggunakan larutan $\mathrm{HCl} 32 \%$ dan $\mathrm{NH}_{4} \mathrm{OH} 25 \%$ sangat efektif untuk mengurangi persen berat unsur-unsur pengotor dan meningkat- 
kan persen berat unsur Fe dan Ti yang merupakan unsur utama pada senyawa Titanomagnetite. Masih adanya unsur $\mathrm{Cl}$ sebesar 11,9547 wt \% sebagai bagian dari garam $\mathrm{NH}_{4} \mathrm{Cl}$ (hasil dari proses ekstraksi kimia) disebabkan oleh proses pencucian (dengan aquades dan alat sentrifugal) endapan hasil proses ekstraksi dengan $\mathrm{NH}_{4} \mathrm{OH}$ yang belum sempurna.

\section{KESIMPULAN}

Dari hasil pembahasan proses model pengajaran material magnetik dan identifikasi senyawa pada pasir alam melalui eksperimen dan analisis prinsipprinsip dasar fisika dengan dukungan teknologi dan lingkungan diperoleh hasil lapangan sebagai berikut. Beberapa sampel yang diambil dari lokasi di Kabupaten Indramayu diperoleh gambaran dari dua jenis pasir yang berbeda lokasi pengambilan mempunyai karateristik berbeda. Sampel pasir muara kaya akan pasir besi (mineral magnetik) yang dalam pengambilan sampelnya kandungan magnetite-nya mencapai 14,712 wt $\%$ dan titanomagnetite mencapai 18,094 $\mathrm{wt} \%$. Sedangkan pada sampel pasir pantai kandungan mineral magnetiknya hanya mencapai sekitar $12 \mathrm{wt} \%$. Proses separasi dengan magnet permanen berkekuatan 0,3 $\mathrm{T}$ berhasil meningkatkan kandungan pasir besi (titanomagnetite) yaitu dengan persen berat mencapai 82,255 wt $\%$. Proses ekstraksi dengan $\mathrm{HCl} 32 \%$ dan $\mathrm{NH}_{4} \mathrm{OH} 25 \%$ yang sebelumnya sudah dilakukan proses milling terlebih dahulu, telah berhasil menghilangkan unsur-unsur pengotor utama yaitu Si. Sedangkan unsur pengotor lainnya yaitu $\mathrm{Al}, \mathrm{P}, \mathrm{S}, \mathrm{V}, \mathrm{Cr}$ hanya menyisakan masing-masing tidak lebih dari $1 \mathrm{wt} \%$.

\section{UCAPAN TERIMA KASIH}

Variasi dalam proses pembelajaran pada materi fisika memerlukan banyak metode agar dapat dengan mudah setiap substansi materi dipahami oleh peserta didik sehingga berbagai upaya dilakukan oleh para pengampu mata pelajaran untuk mencapai tujuan pembelajaran. Penulis mengucapkan banyak terima kasih bagi para pihak yang telah mendukung model pengajaran yang menggunakan analisis prinsip-prinsip fisika di lapangan sehingga terlaksananya proses pembelajaran melalui pengamatan secara langsung yang didukung oleh teknologi serta finansial sehingga tercapainya hasil pengamatan yang terdapat dalam kesimpulan di atas. Penulis/peneliti mengucapkan banyak terima kasih kepada Lembaga Penelitian Universitas Negeri Jakarta atas dukungan finansialnya melalui anggaran Tahun 2008 serta ketua Jurusan yang merekomendasi proses pengajaran melalui penelitian lapangan yang dapat memotivasi peserta didik. Tidak lupa ucapan terima kasih disampaikan kepada kepala Dinas Pendidikan Kabupaten Indramayu beserta staf/teknisi yang memberi bantuan sehingga terlaksanany proses pembelajaran melalui pengamatan langsung dilapangan sampai pada analisis laboratorium yang dapat membantu pemahaman peserta didik dengan baik. Demikian juga kepada kepala laboratorium material di Universitas Negeri Jakarta diucapkan terima kasih atas kesempatan yang diberikan dalam menggunakan fasilitas laboratorium untuk melakukan analisis fisik struktur material magnet yang diambil dari daerah Kabupaten Indramayu tersebut. 


\section{DAFTAR PUSTAKA}

Abd El-All, E. M. 2004. "Paleomagnetism And Rock Magnetism of ElNaga Ring Complex, South Eastern Desert, Egypt". NRIAG Journal of Geophysics, Vol. 3, No. 1, PP. $17-31$.

Aji, M.P. dan Bijaksana, S. 2007. Pembuatan Nanomagnetite dari Bahan Alam Pasir Besi. UNS: Proceedings 4th Kentingan Physics Forum hal. 203-206.

Brown dan Navrotsy. 1994. "Hematiteilmenite $\left(\mathrm{Fe}_{2} \mathrm{O}_{3}-\mathrm{FeTiO}_{3}\right)$ Solid Solutions: The Effects of Cation Ordering ontheThermodynamics of Mixing". American Mineralogist, Volume 7, pages $485-496$.

Evans, Michael. 2003. Enviromental Magnetism. California, USA: Academic Press.

Yulianto, A dan Bijaksana, S. 2002. “Karateriksasi Magnetik dari Pasir Besi Cilacap". Himpunan Fisika Indonesia. Jurnal Fisika HFI. Vol A5 No. 0527.

Omar, M.A. 1975. Elementary Solid State Physics. Addison-Wesley. 